Article

\title{
Numerical Model for Mechanical Nonlinearities of High Manganese Steel Based on the Elastoplastic Damage Model
}

\author{
Seul-Kee Kim ${ }^{1}$, Jong-Hwan Kim ${ }^{2}{ }^{\mathbb{B}}$, Jeong-Hyeon Kim ${ }^{1}$ and Jae-Myung Lee ${ }^{1, *}$ \\ 1 Department of Naval Architecture and Ocean Engineering, Pusan National University, Busan 46241, Korea; \\ kfreek@pusan.ac.kr (S.-K.K.); honeybee@pusan.ac.kr (J.-H.K.) \\ 2 CAE \& PLM Team of Renault Samsung Motors, Gyeonggi-do 17084, Korea; \\ jonghwan1.kim@renaultsamsungm.com \\ * Correspondence: jaemlee@pusan.ac.kr; Tel.: +82-51-510-2342
}

Received: 6 August 2018; Accepted: 27 August 2018; Published: 29 August 2018

check for updates

\begin{abstract}
For constructing marine liquefied natural gas (LNG) fuel/storage tanks, high manganese steel is being recognized as an alternative to stainless steel, nickel alloy, and aluminum alloy. In this study, the nonlinear tensile behavior of high manganese steel was investigated and numerically simulated at cryogenic temperatures at which natural gas exists as a liquid. Physical experimental tensile tests were carried out for a flat test specimen at $293 \mathrm{~K}$ and $110 \mathrm{~K}$. In particular, the tensile behavior of a flat hole-notched high manganese steel specimen was experimentally obtained. A specimen with a hole was readily fractured compared to one without a hole. Tensile behavior of high manganese steel at the two cryogenic temperatures was compared to that of stainless steel, nickel, and aluminum alloy. In addition, numerical tests were performed for flat tensile specimens under identical experimental conditions. The elastoplastic damage model was derived and implemented using an Abaqus user-defined subroutine to appropriately simulate material behavior and degradation. The influence of some parameters on tensile behavior was investigated. The simulation results satisfactorily replicated the nonlinear tensile behavior of high manganese steel. The proposed numerical method, which is based on the damage-coupled material constitutive model, can be applied to structural analysis on the finite element analysis platform considering mechanical nonlinearities induced by severe conditions such as cryogenic temperature.
\end{abstract}

Keywords: high manganese steel; ship's LNG storage tank; cryogenic temperature; material nonlinear tensile behavior; damage-coupled material constitutive model

\section{Introduction}

High manganese steel is an alloy steel with manganese content between 3\% to $27 \%$ that exhibits improved mechanical characteristics and lower cost compared to industrial metallic materials such as mild steel, stainless steel, and aluminum alloy. The material properties of high manganese steel include high strength, toughness at a low temperature, wear resistance, non-magnetic, and high damping. These properties are adjustable depending on relative manganese and carbon content. High manganese steel is applied to various industrial fields based on the aforementioned superior characteristics. In the shipbuilding industry, high manganese steel is being considered an alternative material for fuel tanks that are used to convert fuel to liquefied natural gas (LNG), according to the enhanced International Maritime Organization (IMO) environmental regulations. Pohang Iron and Steel Company (POSCO) developed high manganese austenitic steel that can be used for storage and transport of LNG. This steel can withstand low temperatures thanks to its cryogenic strength and 
toughness [1,2]. Among the steelmaker's claims are its ease of weldability and a cost of $20 \%$ to $30 \%$ below nickel alloy steel, stainless steel, and aluminum alloy alternatives. However, it is well known that natural gas in a liquid state can be retained under $110 \mathrm{~K}$ and materials used to build LNG fuel tanks can withstand this temperature. Therefore, it is essential to investigate the mechanical properties and characteristics of high manganese steel for use in LNG fuel tanks.

Gludovatz et al. conducted tension and fracture toughness tests of high manganese steel at low temperatures. In their study, the stress-strain relations of high manganese steel were acquired experimentally and their results show that high manganese steel exhibits high yield and tensile strength in a range of different temperatures (77 293 K). The fracture toughness in terms of the J-integral was also obtained for a compact tension test specimen at a low temperature and the microstructure of the fractured surface was examined [3]. In addition, there are numerous studies investigating the mechanical behavior of high manganese steel under tension [4-8] and compression [9,10]. Even though most experimental investigations were carried out at room temperature, some studies reported the mechanical behavior of high manganese steel at high [11-15] and low [1-3,15,16] temperatures. In addition to the mechanical properties and behavior, the fracture characteristics $[11,17,18]$, microstructure [19-21], and the impact energy absorption [22,23] were investigated in previous studies. Previously reported results provide sufficient justification regarding the applicability of high manganese steel in the automobile industry. In addition, there are numerous studies that assessed the resistance capacity to loading and deformation as well as its influencing factors such as strength, impact on energy absorption, and phase transformation/precipitation. However, it is difficult to find systematic experimental studies evaluating the material performance of high manganese steel at cryogenic temperatures based on an application to marine LNG tanks. This is because the use of high manganese steel in LNG fuel tanks has recently become feasible and establishing test facilities is limited by the cost and time required to construct a cryogenic environment for testing. Considering testing at structural levels, this limitation will become more serious.

Figure 1 shows the typical relationships between stress and strain in high manganese steel under tension at room and low temperatures. The material behavior of high manganese steel exhibits different features compared with general industrial metals such as carbon (mild) steel. As shown in Figure 1, high manganese steel exhibits strong work hardening behavior at room temperature and low temperatures. The ultimate tensile strength of high manganese steel increases noticeably at a low temperature and is accompanied by a small reduction in elongation. Moreover, one should note that the rapid degradation represented by a necking-failure phenomena occurred immediately after reaching the tensile strength. Earlier studies reported that microstructural effects such as martensite formation and mechanical twinning contributed to the strengthening of high manganese steel and delayed the onset of necking, which is associated with large uniform elongation [24-29]. Based on these features, strength-based design is typically performed for industrial structures and can lead to structural safety problems with respect to excessive deformation and rapid necking-fracture in high manganese steel. Therefore, it is important to consider the mechanical behavior at a low temperature when using high manganese steel in structural design. However, structural analysis is restricted to reflecting the nonlinear behavior of high manganese steels using finite element analysis (FEA) with typical constitutive models built into commercial FEA programs. Previous studies that aimed for the development and the application of constitutive equations expressing the behavior of high manganese steels at low temperatures are insufficiently reported. 


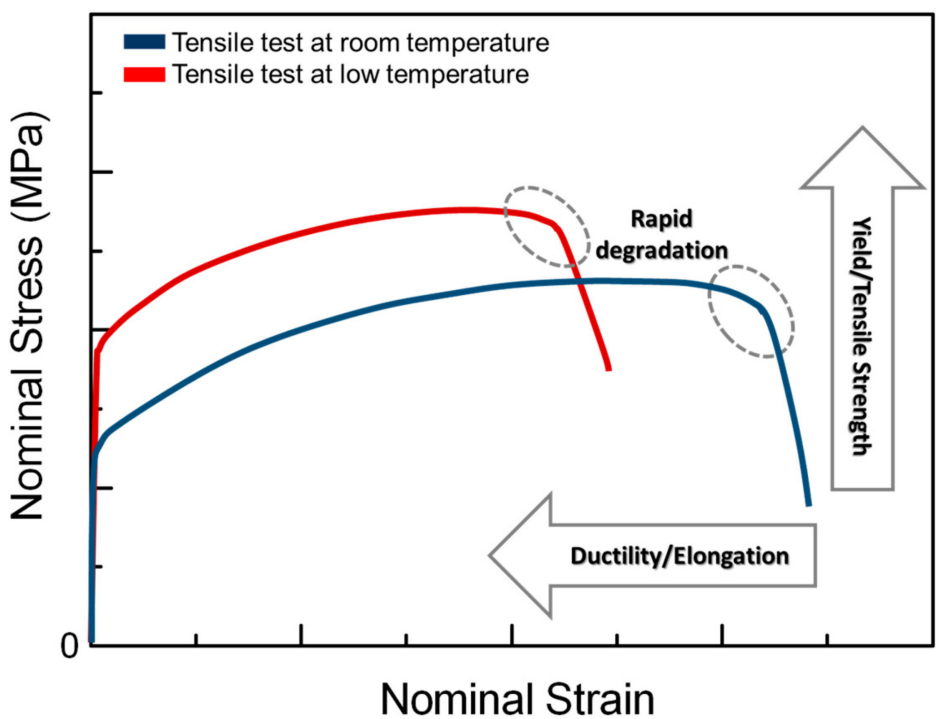

Figure 1. Typical constitutive relation of high manganese steel at room temperature and low temperatures.

Meanwhile, several theoretical/computational studies on the development and application of material models have been carried out based on continuum damage mechanics, which was introduced as a method for expressing a nonlinear behavior and a degradation-failure behavior after reaching an ultimate tensile strength [30]. Damage mechanics is based on thermodynamic micromechanical approaches and has provided governing equations that can be incorporated into a material constitutive model. This facilitates examinations of degradation resulting in crack initiation and propagation [31-33]. Moreover, a damage-coupled constitutive model in FEA is recognized as an effective method to describe the nonlinear behavior of a material without true stress-strain data because an inconvenient process for converting to true stress-strain data is required when using experimentally obtained data (engineering stress-strain relation) during FEA [34,35]. Different methods should be considered for this conversion process in accordance with the type of material and specimen shape. However, a damage coupled constitutive model provides the appropriate material behavior data for a variety of materials and test conditions in FEA by adjusting the hardening function and material parameters. Owing to these advantages, the author [36] proposed a viscoplastic damage model, which could describe the tensile behavior of a specimen with a hole and predict a fracture for stainless steel 304L (SUS304L) at cryogenic temperatures. In addition, Kim et al. [37] investigated the pre-strain and temperature effects for a corrugated sheet of SUS304, which is used in Mark-III type LNG carrier containment systems, by using a constitutive damage model with FEA. It turns out that the proposed model can effectively express the tensile behavior of the target structure. Similarly, a more effective computational evaluation could be possible if a damage model describing the behavior of high manganese steel is developed and combined with FEA for various structures to be designed with high manganese steel.

Therefore, in the present study, a computational method for simulating the tensile behavior of high manganese steel was conducted based on damage-coupled FEA. A damage-coupled material constitutive model, which can express work hardening and rapid degradation of high manganese steel at room and cryogenic temperatures, was introduced and implemented into the Abaqus (6.13, Dassault Systèmes Simulia Corp, Johnston, Rhode Island, USA) user-defined material subroutine (UMAT). Material tensile tests were conducted to identify the mechanical behavior of high manganese steel and determine the material parameters in the constitutive model. Computational simulations of tensile tests for a high manganese steel specimen with a center hole were performed at room and cryogenic temperatures. The simulated load-displacement curves were compared with experimental results in order to verify the effectiveness of the proposed computational method. In conjunction with the proposed computational method, tensile test results at a cryogenic temperature can provide the 
experimental background required to evaluate the feasibility of using high manganese steel in marine LNG fuel tanks. Demand for high manganese steel LNG fuel tanks by the shipbuilding industry is expected to increase.

\section{Material Tensile Test of High Manganese Steel}

The nonlinear tensile behavior of high manganese steel was experimentally investigated in this study. Regarding the adoption of high manganese steel in marine LNG fuel and storage tanks, tests were performed at room $(293 \mathrm{~K})$ and cryogenic $(110 \mathrm{~K})$ temperatures. The experimental stress-strain relationship was compared with tensile behavior of stainless steel, nickel alloy, and aluminum alloy since these materials are commonly used to construct LNG-related industrial structures. The obtained mechanical properties and tensile behavior were also applied to a stage of numerical tensile tests in this study as calibration and validation data.

\subsection{Experimental Tensile Test Preparation}

A specimen of high manganese steel was prepared for an experimental tensile test. The chemical composition of the target material is summarized in Table 1 and the composition of manganese and carbon contents in the target material is $23.70 \mathrm{wt.} \%$ and $0.37 \mathrm{wt} . \%$, respectively. Figure 2 shows a schematic of the tensile test specimen with its specific dimensions and a flat type tensile test specimen was fabricated in accordance with the KS B0801 standard.

Table 1. The chemical composition of high manganese steel (wt.\%).

\begin{tabular}{rcccccccc}
\hline Element & $\mathbf{C}$ & $\mathbf{S}$ & $\mathbf{S i}$ & $\mathbf{C r}$ & $\mathbf{M n}$ & $\mathbf{C u}$ & $\mathbf{P}$ & Sol-Al \\
\hline Weight $\%$ & 0.3682 & 0.0016 & 0.184 & 3.073 & 23.704 & 0.511 & 0.0205 & 0.0444 \\
\hline
\end{tabular}

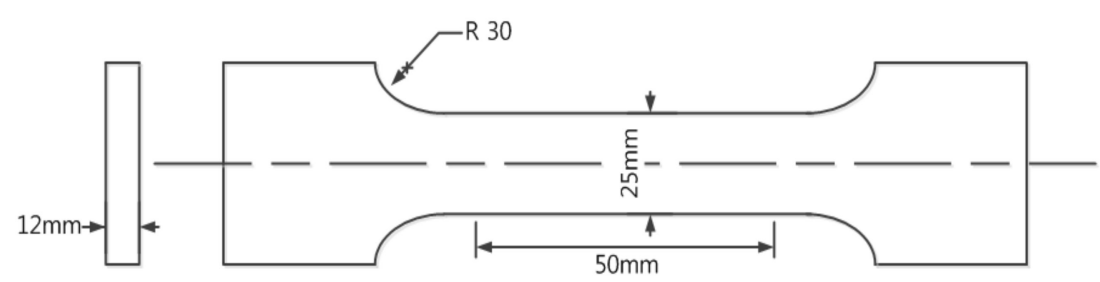

Figure 2. Schematics of a flat type tensile test specimen (KS B0801 10).

A universal testing machine (UH-1000kN, Shimadzu, Kyoto, Japan) was used for tensile testing and the experimental apparatus is shown in Figure 3. The experiment was carried out at room (293 K) and cryogenic $(110 \mathrm{~K})$ temperatures. Liquid nitrogen was sprayed into a specially designed cryogenic chamber in order to maintain the temperature at $110 \mathrm{~K}$ during the cryogenic test. The cryogenic temperature was verified with a thermometer and a control system inside the chamber was used to automatically adjust the amount of liquid nitrogen injected during testing. During the cryogenic test, a pre-cooling treatment was conducted for $1 \mathrm{~h}$ to stabilize the thermal gradient in the specimen. The displacement rate during the tensile test was set to $3 \mathrm{~mm} / \mathrm{min}$ at both temperatures and a cryogenic extensometer (3542-050-100-LT, Epsilon Technology Co., Jackson, WY, USA) was installed in the middle of the specimen to measure the deformation during the tensile test. For greater reliability of test results, each test case was replicated five times for a different specimen. 


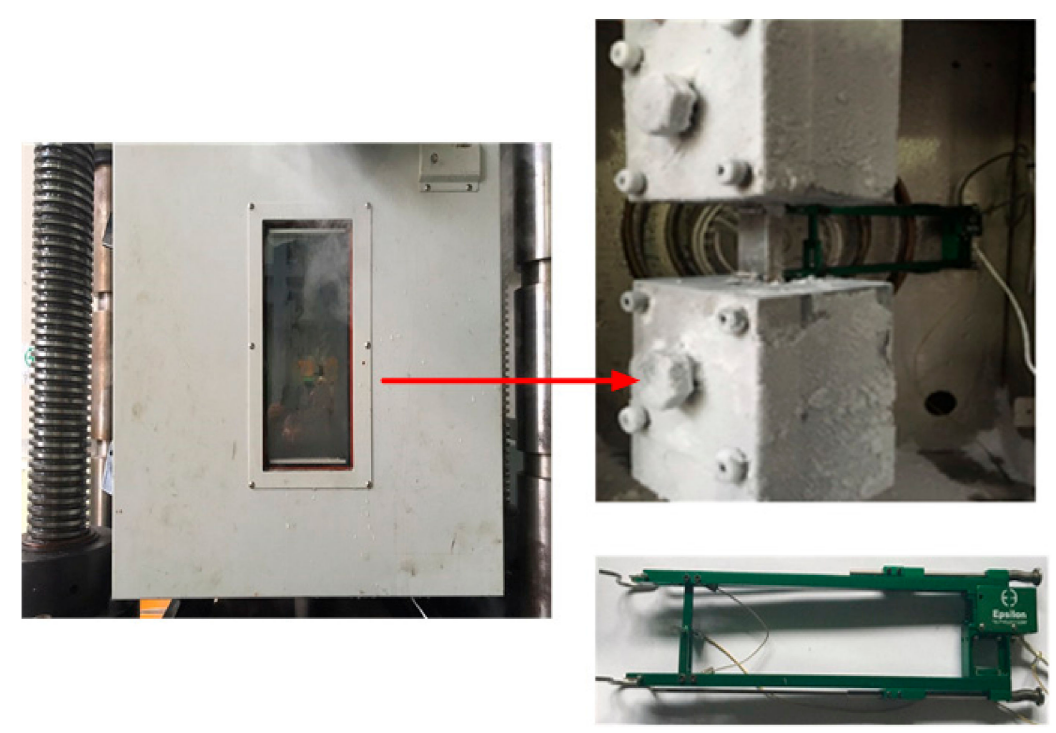

Figure 3. Experimental apparatus for a tensile test for high manganese steel.

\subsection{Tensile Behavior of High Manganese Steel at a Cryogenic Temperature}

As a test result, the stress-strain behavior of high manganese steel was compared at different temperatures. Figure 4 shows representative results that were obtained from three of five test datasets. The remaining two datasets, which deviated from the mean value of the tensile strength, were excluded to reduce the experimental error. The test results at room temperature indicate a large elongation over $60 \%$ with a similar tendency one would see in a stress-strain graph of a typical ductile material. Stress increased linearly in the elastic region. Hardening was observed when the yield point was reached. This occurs because high manganese steel induces mechanical twinning during plastic deformation in the austenite structure, which leads to great increases in strength and elongation. Moreover, the fraction of $\varepsilon$-martensite increases inside the materials owing to continuous tensile loading and hardening persists because a lot of energy must be consumed during the phase transformation. In the case of martensite, however, this has a large impact on increasing strength rather than ductility. Thus, high manganese steel has a fracture without a large deformation after the maximum tensile strength is reached unlike a typical ductile material [38].

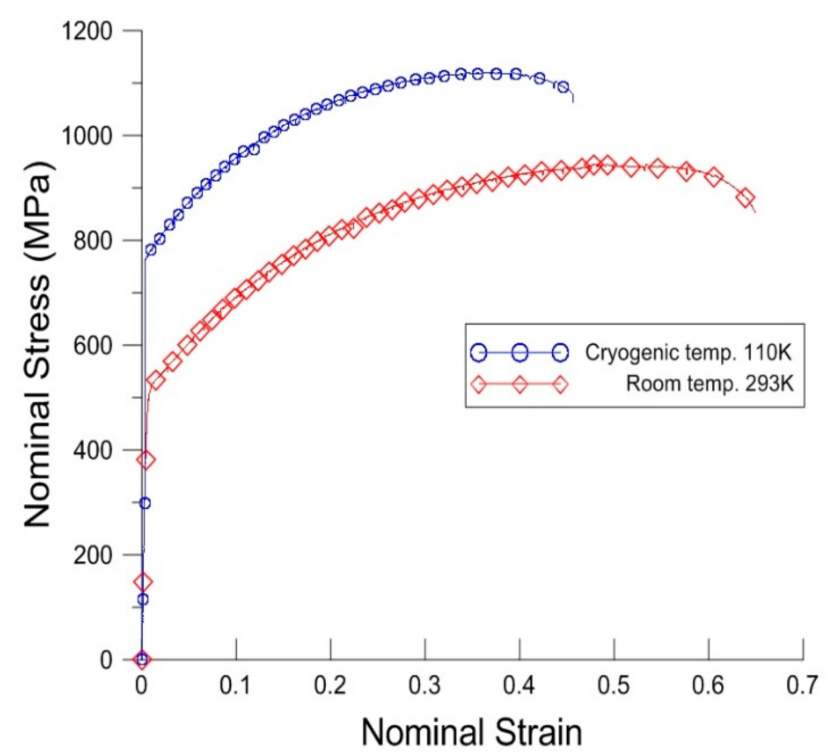

Figure 4. Representative tensile test results of high manganese steel at room and cryogenic temperatures. 
On the other hand, it was confirmed that elongation decreased significantly while strength increased at the cryogenic temperature. This was led by a quick phase deformation into $\varepsilon$-martensite and $\alpha^{\prime}$-martensite. The $\alpha^{\prime}$-martensite phase also exhibits superior strength but not ductility.

Figure 5 shows the stress-strain curves at $110 \mathrm{~K}$ for high manganese steel, SUS304L, 7\% nickel steel, and Al5083 alloy in the cryogenic environment. These stress-strain data were quoted from Park et al. [39] and Kim et al. [40], respectively. First, SUS304L exhibited strong hardening behavior associated with transformation-induced plasticity at the cryogenic temperature. In particular, SUS304L exhibited a lower yield stress than high manganese steel and 7\% nickel steel, but it also exhibited the highest maximum tensile strength ( 1300 MPa). For 7\% nickel steel, there wasn't any significant hardening effect and the nominal stress steadily decreased with a low-stress level after the maximum tensile strength was reached while the steel exhibited the highest yield stress. On the other hand, the Al5083 alloy exhibited a similar behavior to the high manganese steel sample. However, its yield stress and maximum tensile strength were insufficient for structural safety. Lastly, the strength and behavior of high manganese steel was much more reliable and stable than the other materials. Thus, using high manganese steel as substitutes for the above-mentioned materials would guarantee structural integrity. However, the decreased elongation in a cryogenic environment could be a risk factor in terms of allowable deformation. Therefore, a sufficient examination of the appropriate usage environment should be considered before high manganese steel is used in real applications.

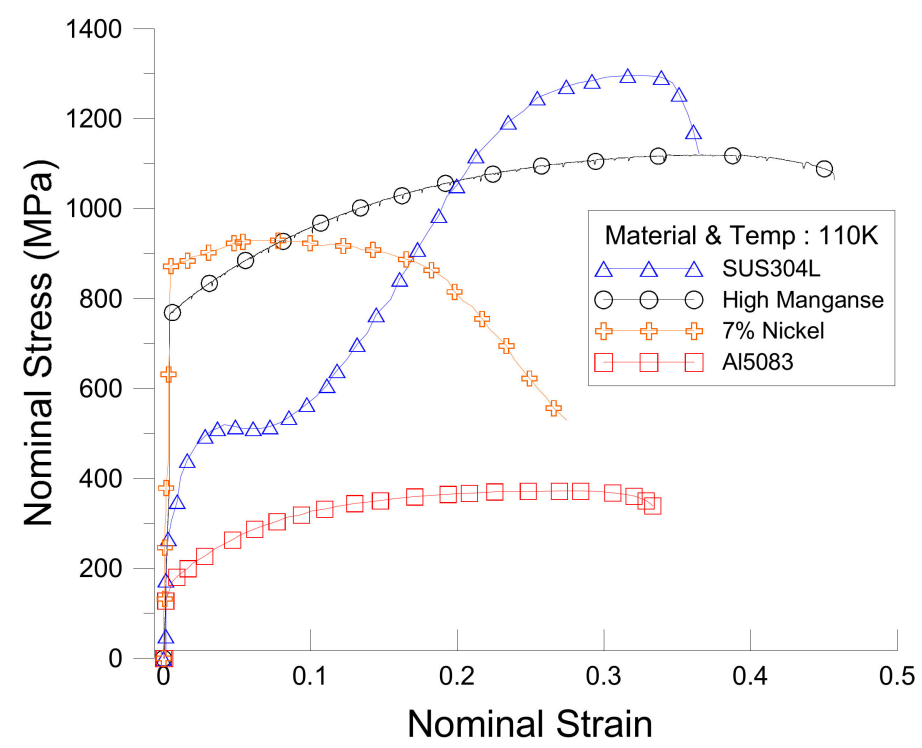

Figure 5. Representative results of the tensile test at a cryogenic temperature $(110 \mathrm{~K})$ for different materials: High manganese steel, stainless steel 304L, 7\% Nickel and Al5083 alloy.

\section{Elastoplastic Damage Model for High Manganese Steel}

\subsection{Elastoplastic Damage Model and Implicit Formulation}

The Lemaitre damage model describes the material damage as the degradation of the elastic modulus affected by the growth of internal voids and micro-cracks, which define the damage internal state variable as $D$. It is then expressed with the general Hooke's law shown in Equation (1).

$$
\boldsymbol{\sigma}=(1-D) \mathbf{D}: \varepsilon^{\mathrm{e}}
$$

where $\varepsilon^{\mathrm{e}}$ signifies the elastic strain and $\mathbf{D}$ signifies the elasticity stiffness tensor for the isotropic material. The $D$ value of the undamaged material is 0 . It is built up by gradually relying on the load 
duration to the material. The division of the stress tensor by a stress component of deviatoric stress and hydrostatic stress is expressed in Equations (2) and (3).

$$
\begin{gathered}
\mathbf{s}=(1-D) 2 G \mathbf{e}^{\mathrm{e}} \\
p=(1-D) K \mathbf{v}^{\mathrm{e}}
\end{gathered}
$$

where $G$ signifies the shear modulus, $K$ signifies the bulk modulus, and $\mathbf{e}^{\mathrm{e}}$ and $\mathbf{v}^{\mathrm{e}}$ signify, respectively, the deviatoric strain tensor and volumetric strain tensor. The kinematic hardening un-shows a practical effect in the uniaxial direction of the load so that the simplified Lemaitre damage model ignores the kinematic hardening. The corresponding yield function based on the von Mises model is shown in Equation (4).

$$
\Phi=\frac{q}{1-D}-\sigma_{y}(R)
$$

where $q$ signifies the von-Mises equivalent stress, $R$ signifies the isotropic hardening internal variable, and $\sigma_{y}$ signifies the hardening function for the isotropic hardening behavior. The total strain is indicated by $\varepsilon=\varepsilon^{\mathrm{e}}+\varepsilon^{\mathrm{p}}$, which is the sum of strain in the elastic and plastic region. The corresponding increment form is then described by the formula presented in Equation (5).

$$
\dot{\varepsilon}=\varepsilon^{\dot{e}}+\dot{\varepsilon}^{p}
$$

The direction of the plastic strain increment is vertical to the tangential direction of the yield function by using the plasticity flow theory. This could be carried out by the Equation (6).

$$
{ }_{\varepsilon^{p}} \dot{p}=\dot{\gamma} \frac{\partial \Phi}{\partial \sigma}
$$

where $\dot{\gamma}$ signifies the plastic multiplier, which influences the evolution of an internal variable. The equations related to the damage evolution in the Lemaitre damage model are presented in Equations (7)-(9).

$$
\begin{gathered}
\dot{R}=\dot{\gamma} \\
\dot{D}=\dot{\gamma} \frac{1}{1-D}\left(\frac{-Y}{r}\right)^{s} \\
Y=\frac{1}{2(1-D)^{2}} \sigma: \mathbf{D}^{-1}=\frac{-q^{2}}{6 G(1-D)^{2}}-\frac{p^{2}}{2 K(1-D)^{2}}
\end{gathered}
$$

where $Y$ signifies the damage energy release rate and $r$ and $s$ are the material parameters associated with the damage evolution.

This research adopts the implicit elastic predictor/return mapping method for the numerical implementation of the elastoplastic damage model [41]. Below, we illustrate the key steps of the finite element formulation process.

- Step 1: the strain and trial stress are shown in Equations (10) and (11). Assume that the damage variable $D$ and growth of the internal variable $R$ do not appear in the elasticity region (Equations (12) and (13)).

$$
\begin{gathered}
\mathcal{\varepsilon}^{\mathrm{e} \text { trial }}=\varepsilon^{\mathrm{e}}{ }_{\mathrm{n}}+\Delta \varepsilon \\
\boldsymbol{\sigma}^{\text {trial }}=\left(1-D_{n}\right) \mathbf{D}: \varepsilon^{\mathrm{e} \text { trial }} \\
R^{\text {trial }}=R_{\mathrm{n}} \\
D^{\text {trial }}=D_{\mathrm{n}}
\end{gathered}
$$


- Step 2: Calculate the von-Mises equivalent stress, $q$, and the hydrostatic stress, $p$ as presented in Equations (14) and (15), respectively. The effective equivalent stress $\widetilde{q}$ and effective hydrostatic stress $\widetilde{p}$ are defined in Equations (16) and (17), respectively.

$$
\begin{gathered}
q^{\text {trial }}=\left(\frac{3}{2} \varepsilon^{\text {trial }}: \varepsilon^{\text {trial }}\right)^{1 / 2} \\
p^{\text {trial }}=\frac{1}{3} \sigma^{\text {trial }}: I \\
\widetilde{q}^{\text {trial }}=\frac{q^{\text {trial }}}{1-D_{\mathrm{n}}} \\
\tilde{p}^{\text {trial }}=\frac{p^{\text {trial }}}{1-D_{\mathrm{n}}}
\end{gathered}
$$

- Step 3: Compute the yield function value using Equation (18) and check the yield condition.

$$
\Phi^{\text {trial }}=\widetilde{q}^{\text {trial }}-\sigma_{y}(R)
$$

If $\Phi^{\text {trial }} \leq 0$ is met, it becomes $\sigma_{\mathrm{n}+1}=\boldsymbol{\sigma}^{\text {trial }}$ because the stress condition is contained by the elastic region. The other variables are updated as $(\cdot)_{\mathrm{n}+1}=(\cdot)^{\text {trial }}$. Finish the numerical calculation on a time increment. If $\Phi^{\text {trial }}>0$ is true, in reverse, the stress condition corresponds by the plastic region. Then, perform step 4 .

- $\quad$ Step 4: the modified calculation of $(\cdot)_{n+1}$ considering the plastic region through return mapping is carried out as shown in Equations (19-24).

$$
\begin{gathered}
\mathcal{\varepsilon}^{\mathrm{e}}{ }_{\mathrm{n}+1}=\varepsilon^{\mathrm{e} \text { trial }}-\Delta \gamma \sqrt{\frac{3}{2}} \frac{\mathbf{s}_{\mathrm{n}+1}}{\left(1-D_{n+1}\right)\left\|\mathbf{s}_{\mathrm{n}+1}\right\|} \\
R_{\mathrm{n}+1}=R_{\mathrm{n}}+\Delta \gamma \\
\frac{q_{n+1}}{\left(1-D_{\mathrm{n}+1}\right)}-\sigma_{y}\left(R_{\mathrm{n}}+\Delta \gamma\right)=0 \\
q_{n+1}=\left(1-D_{\mathrm{n}+1}\right) \bar{q}^{\text {trial }}-3 G \Delta \gamma \\
D_{\mathrm{n}+1}-D_{\mathrm{n}}-\frac{\Delta \gamma}{1-D_{\mathrm{n}+1}}\left(\frac{-Y_{n+1}}{r}\right)^{\mathrm{s}}=0 \\
-\gamma\left(\Delta \gamma, D_{\mathrm{n}+1}\right)=\frac{\left[\left(1-D_{\mathrm{n}+1}\right) \widetilde{q}^{\text {trial }}-3 G \Delta \gamma\right]^{2}}{6 G\left(1-D_{\mathrm{n}+1}\right)^{2}}+\frac{\widetilde{p}_{n+1}{ }^{2}}{2 K}
\end{gathered}
$$

Find the $\Delta \gamma$ value satisfying Equations (21) and (23) using the Newton-Raphson method.

- Step 5: Renew the variables of Step 4 based on the calculated $\Delta \gamma$.

- Step 6: End the calculation using a time increment. Repeat the above process for the new calculation using a time increment.

The finite element formulation process about the previously mentioned damage model is coded into the FORTRAN language and is mounted on UMAT (User-defined Material Subroutine) that Abaqus/Standard, Commercial Finite Element Analysis Software (6.12, Dassault Systems, Vélizy-Villacoublay, France). 


\subsection{Investigation of the Material Parameter Effect on Tensile Behavior}

Tensile testing was simulated in order to verify the proposed UMAT. First, boundary conditions that mimic the practical tensile test were applied to a flat bar specimen. One edge was fixed to control movement and the other edge was allowed to move through displacement control. Moreover, a half-sized model of the tensile testing specimen was used for computational efficiency and a symmetric condition was applied accordingly. The three-dimensional eight-node reduced integration element was chosen, which has 2148 elements and 3081 nodes. The finite element model and the applied boundary conditions are shown in Figure 6.

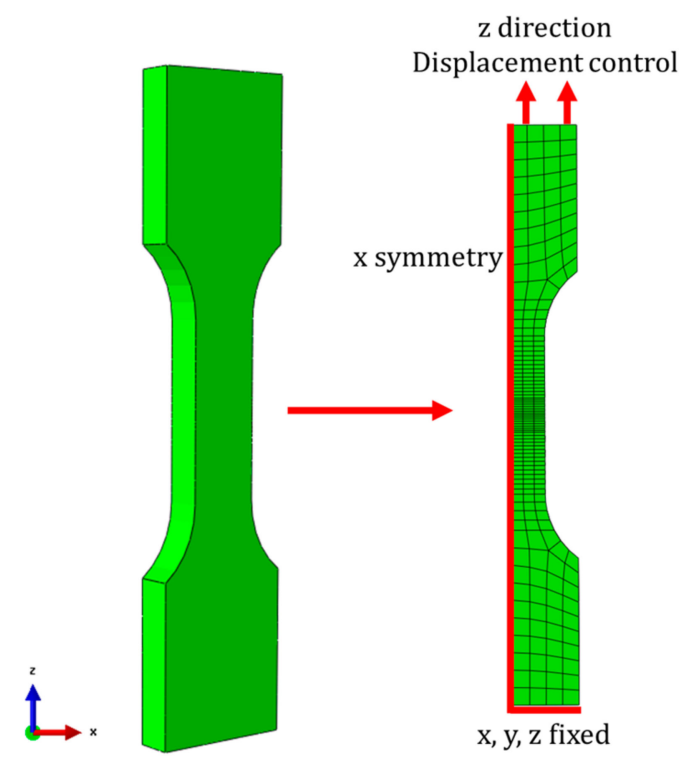

Figure 6. Finite element model of the tensile specimen (flat bar type) for ABAQUS user-defined material subroutine (UMAT).

The determination of material parameters $r$ and $s$ is one of the most important points and could draw dispute. For ductile materials, $s=1$ is commonly used and $r$ is taken as the value obtained from test results. In some ductile materials, however, it could be impossible to express the behavior corresponding with test results when $s=1$. To solve these problems, a study that proposes a modified damage potential function has been carried out. Nonetheless, the model formulation needs to be revised in accordance with the new potential function instead of the existing finite element formulation process, which has no impact on efficiency. Thus, we used the proper $s$ to assure that the behavior of the material could be accurately simulated [42,43].

Figure 7 shows that a numerical tensile test results in terms of the load-displacement curves while varying the material parameters. The load-displacement curves are similar as $r$ increases. Adjusting the total displacement to fracture is possible by increasing $r$. On the other hand, the behavior changed somewhat since $s$ was varied especially when examining material fracture. A sharp drop in load was observed when $s$ decreased. Therefore, by adequately controlling the values of $r$ and $s$, the simulation results should coincide with the experimental results. We find that the values of $r$ and $\mathrm{s}$ must be relatively high in the case of high manganese steel. However, if the value of $r$ and $s$ increase, the evolution of $D$ is slow as $r$ changes when the initial load is applied and increases exponentially around the time when rupture occurs due to the high value $s$. This leads us to have the $D>1$ area value as the damage value, which is defined as $0 \leq D \leq 1$ in the numerical calculation. In other words, it could be verified that the convergence fell dramatically. 

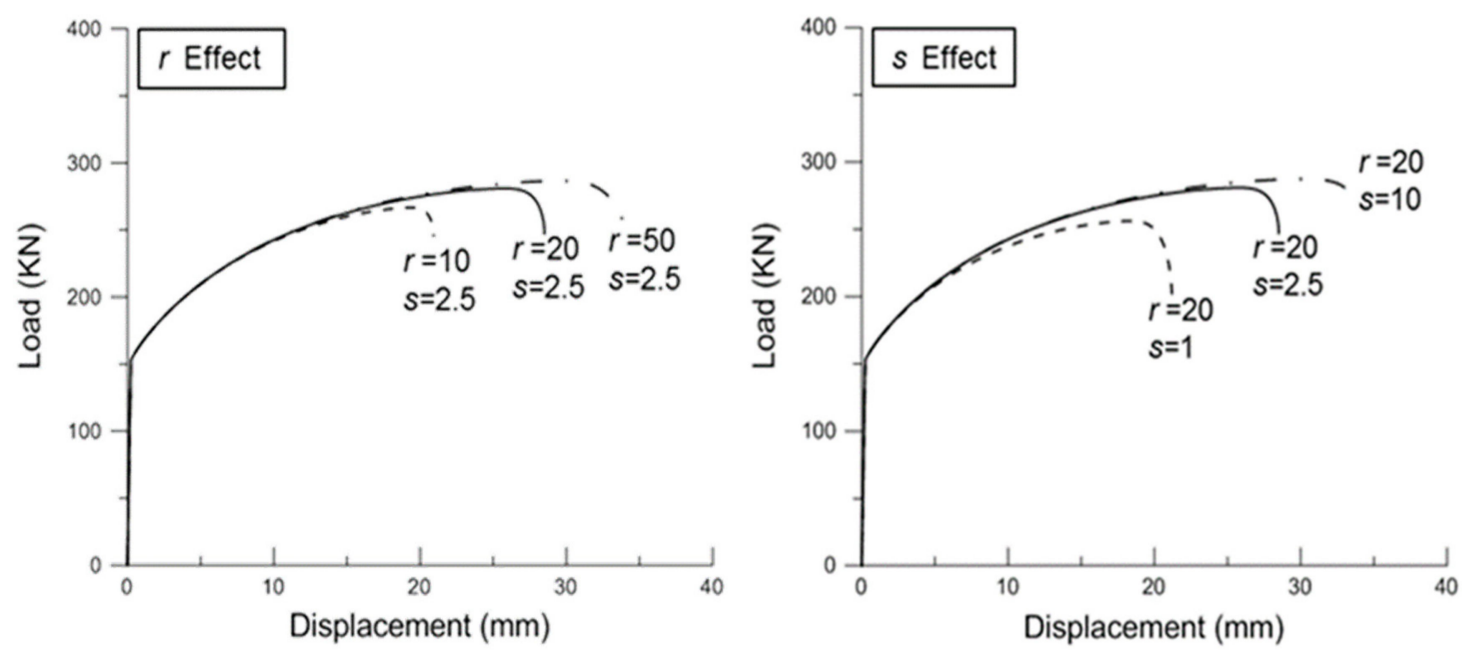

Figure 7. Load-displacement relations with respect to varying material parameter $r$ (left) and $s$ (right).

\subsection{Modification of the Damage Model}

It was carried on to show how the material parameters $r$ and $s$ relate to damage evolution and affect the material behavior. The aforementioned procedure for determining $r$ and $s$ shows that the FEA results could better replicate the material behavior of high manganese steel by introducing a modification factor $k$, which represents delayed damage evolution and improves convergence. The constitutive equation was reduced to a single nonlinear equation by applying the one-equation integral algorithm proposed by De Souza [33]. This method has been reported to enhance convergence and computational efficiency [33]. The governing equation regarding damage evolution is shown in Equation (25).

$$
\dot{D}=k \frac{\Delta \gamma}{1-D}\left(\frac{-Y_{n+1}}{r}\right)^{s}
$$

In this scenario, $0 \leq k \leq 1$, and the introduction of $k$ forms a modified Lemaitre model. The material integrity was defined as $\omega$ for convenience. Using the above definition, Equations (21) and (23) could be expressed by Equations (26) and (27).

$$
\begin{gathered}
\omega \equiv 1-D \equiv \frac{3 G \Delta \gamma}{\widetilde{q}^{\text {trial }}-\sigma_{y}\left(R_{\mathrm{n}}+\Delta \gamma\right)} \\
\omega_{n+1}-\omega_{n}-k \frac{\left[\widetilde{q}^{\text {trial }}-\sigma_{y}\left(R_{\mathrm{n}}+\Delta \gamma\right)\right]}{3 G}\left(\frac{-\gamma(\Delta \gamma)}{r}\right)^{s}=0
\end{gathered}
$$

By combining Equations (26) and (27) and using the Newton-Raphson method, the proper value of $\Delta \gamma$ is obtained. When the Newton-Raphson method is introduced to obtain a proper numerical approximation, it is normal to set the initial value of $\Delta \gamma$ to 0 . To improve convergence, however, $\Delta \gamma^{(0)}$ is defined as shown in Equation (28).

$$
\Delta \gamma^{(0)}=\frac{\left[\widetilde{q}^{\text {trial }}-\sigma_{y}\left(R_{\mathrm{n}}\right)\right] \omega_{n}}{3 G}
$$

\section{Numerical Tensile Test}

\subsection{Cryogenic Tensile Test for a Flat Bar Specimen}

The material parameters and hardening function in the proposed model, which were obtained from tensile test results, are listed in Table 2. The yield strength and material parameters were applied because the test at $110 \mathrm{~K}$ results in increased strength and decreased elongation in comparison with the 
test at room temperature. The presented yield function and material parameters, however, are not the only values that could express the nonlinear behavior of high manganese steel. Therefore, it is possible to derive the true variable set after analyses of results from numerous experiments such as the tension behavior, compression, shearing, torsion, and more.

Table 2. Material parameters of the elastoplastic damage model.

\begin{tabular}{ccc}
\hline Parameter & $\mathbf{2 9 3} \mathbf{~ K}$ & $\mathbf{1 1 0 ~ K}$ \\
\hline Young's modulus, $E$ & $175 \mathrm{GPa}$ & $175 \mathrm{GPa}$ \\
Poisson's ratio, $v$ & 0.3 & 0.3 \\
Yield strength, $\sigma_{y 0}$ & $520 \mathrm{MPa}$ & $780 \mathrm{MPa}$ \\
Damage parameter, $\mathrm{s}$ & 4.7 & 8.3 \\
Damage parameter, $r$ & $20.0 \mathrm{MPa}$ & $15.2 \mathrm{MPa}$ \\
Correction factor, $k$ & 0.76 & 0.81 \\
\hline
\end{tabular}

Figure 8 shows a comparison among the results from the modified Lemaitre model acquired from tensile testing simulations, the von Mises model without consideration of the damage, and experimental load-displacement results. The von Mises model shows that the displacement increases as loads increase while the modified Lemaitre model shows behavior that is similar to the test results. The initial load dropped dramatically and convergence was low because damage was almost nonexistent as $r$ grows in the existing model. However, damage increased sharply within the fractured area. On the other hand, the modified model exhibits improved convergence and better reflects the observed behavior due to the delayed damage evolution. A graph of damage was extracted from the simulation combined with the modified model at the center node of the specimen. The result is shown in Figure 9a. The early part of the plastic zone was not reached and deformation began rising beyond the maximum tensile strength until the specimen finally fractured. The damage evolution is closely connected with stress triaxiality, which is expressed as the proportion of hydrostatic pressure stress and von Mises equivalent stress. This is shown in Equation (29).

$$
\sigma_{\mathrm{T}}=\frac{p}{q}
$$

Uniaxial stress is dominant during tensile testing before reaching the maximum tensile strength, but the occurrence of multiaxial stress and increased stress triaxiality occur owing to a decrease in the cross-sectional area from necking. This causes the damage evolution and results in a material fracture [44].

Figure $9 \mathrm{~b}$ shows the damage contour and stress triaxiality while the tensile load is applied. One can see that the sides and the middle of the specimen have steady damage constants while the initial uniform uniaxial stress is applied. However, the maximum damage value moves to the inner region due to necking, which indicates a transformation to multiaxial stress. Stress triaxiality also increased. Thus, it is expected that the material started to fracture from the innermost parallel middle portion and the fracture subsequently extends to the outer edges. 


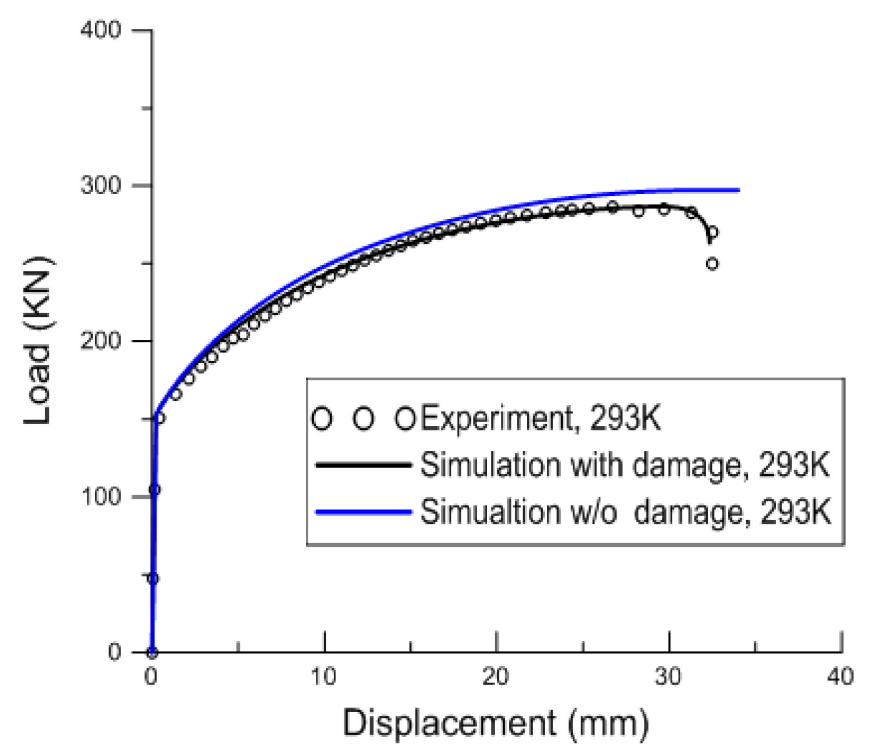

Figure 8. Comparison of load-displacement relations obtained from experimental and numerical tensile tests at room temperature.

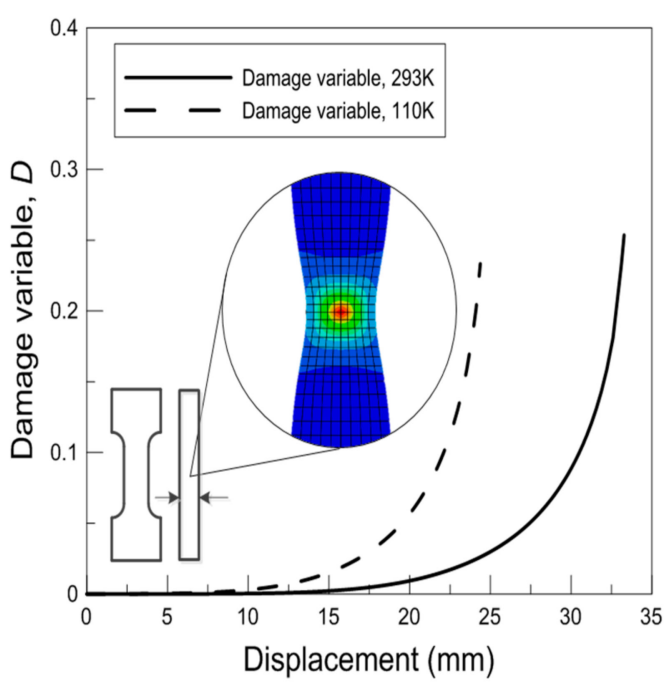

(a)

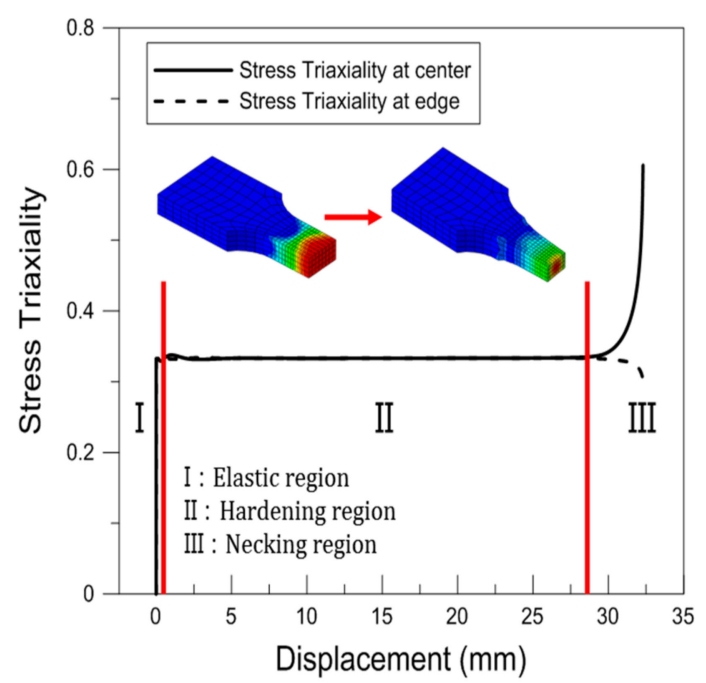

(b)

Figure 9. (a) Growth of the damage variable at the center node of the specimen under room and cryogenic temperatures. (b) Damage contour on the specimen and the stress triaxiality-displacement relation during tensile loading.

\subsection{Cryogenic Tensile Test for a Hole-Notched Flat Bar Specimen}

Inclusion of a hole as the most general form of a notch has been used for various purposes in engineering fields. The material exhibits behavior that is different from the natural material properties due to the effect of the notched hole. Therefore, the tensile specimen with a notch hole was also simulated for validation of the proposed model. Tensile testing of a specimen with an $8 \mathrm{~mm}$ hole near the center of the bar was conducted at room temperature and in the cryogenic environment. The experimental results were compared with simulation results. A notched hole was inserted in the tensile test specimen and the same general tensile testing procedure was applied to this model, which is shown in Figure 10. The element used was a three-dimensional eight-node reduced integration (C3D8R), which has 4432 elements and 5823 nodes. Moreover, the material parameters and hardening function used in the notch simulation were equal to the values used in the previous basic tensile simulation. 


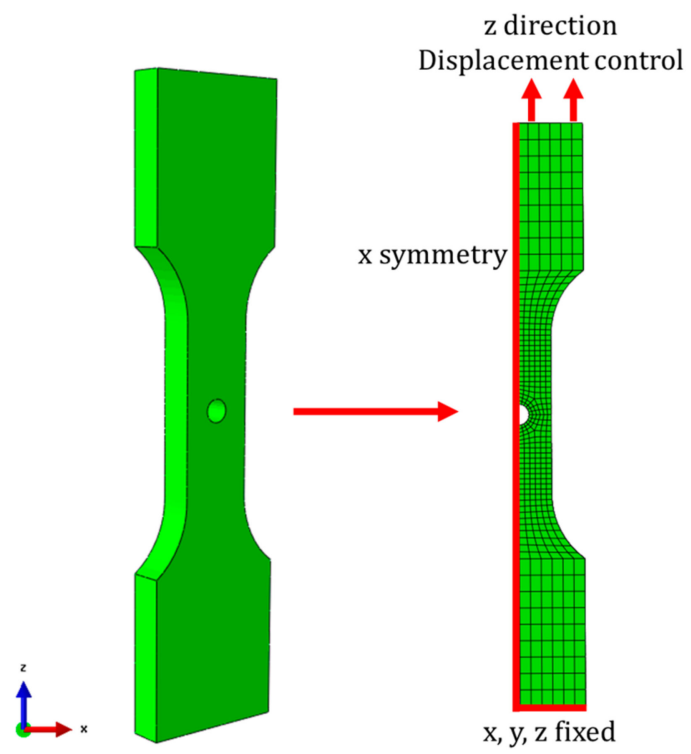

Figure 10. Finite element model of the tensile specimen (hole-notched flat bar) for Abaqus UMAT.

Figure 11a shows the simulated load-displacement results and the experimental results from the basic tensile tests and the notch test at room and cryogenic temperatures. In the case of the hole-notched specimen, the stress-strain curves show small displacement and lower load level than the basic tensile test results, which is owed to the presence of the hole. The damage variable also evolved at one node in accordance with plastic deformation and fracture, which is shown in Figure 11b. It turns out that a complex interaction occurs between the hole-notch and the overall geometry, which degrades the strength and hardening of the material. As a result, the tensile simulation results confirm the fact that the proposed UMAT model could effectively express the overall tensile behavior of high manganese steel.

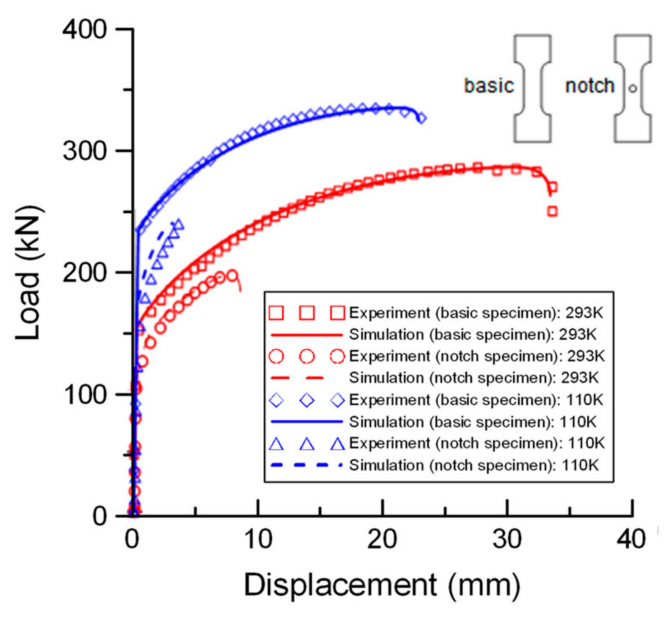

(a)

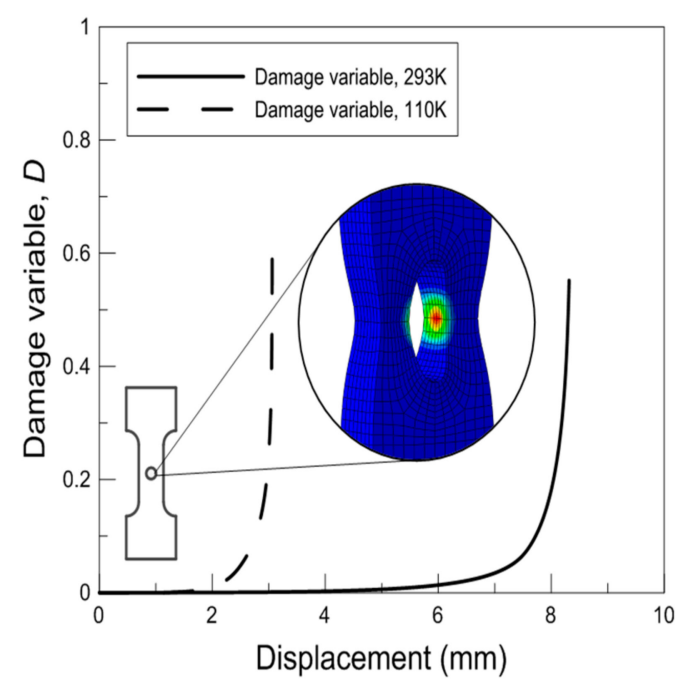

(b)

Figure 11. (a) Comparison of load-displacement relations obtained from experimental and numerical tensile tests for flat bar and hole-notched flat bar specimens. (b) Growth of the damage variable at around the center hole under room and cryogenic temperatures. 


\section{Conclusions}

This paper shows the nonlinear behavior of high manganese steel by applying FEA to the elastoplastic damage model. The mechanical properties were obtained from experimental tensile tests of high manganese steel. Moreover, the elastoplastic damage model was implemented in UMAT provided by Abaqus and was solved with FEA. The FEA results were validated by comparing them with tensile test results. The analysis result in this paper is summarized below.

- We performed the tensile testing of high manganese steel at room and cryogenic temperatures $(110 \mathrm{~K})$ in order to investigate the applicability of this material in a cryogenic environment. The strength of high manganese steel was found to be superior to SUS or nickel steel, which is used in existing LNG cargo containment systems. However, a sufficient review should be performed in advance of the application due to the decreased elongation. The material properties and material parameters obtained from these tests were used in subsequent simulations.

- The modified elastoplastic damage model was coded in FORTRAN through finite element formulation and was embedded with UMAT in Abaqus. The system was simulated under the same conditions as the experimental tensile tests and the results were displayed in a load-displacement graph. The simulation results were compared with the tensile test result and the simulation effectively replicated the nonlinear behavior of high manganese steel.

This research focused on the tensile behavior of high manganese steel. Therefore, in order to develop a model that could computationally estimate the behavior of a structural unit, additional tests such as compression, shearing, torsion, and more should be conducted.

Author Contributions: S.-K.K. and J.-H.K. (Jong-Hwan Kim) conducted experimental and numerical tests. J.H.K. (Jong-Hwan Kim) aided in the description of the material constitutive model and implementation into FEA. J.-H.K. (Jeong-Hyeon Kim) analyzed the test data. J.-M.L. conceived the paper and supervised the theoretical and numerical processes described in the paper.

Funding: The authors received no financial support for the research, authorship, and/or publication of this article.

Acknowledgments: This work was supported by the National Research Foundation of Korea (NRF) grant funded by the Ministry of Science and ICT (MSIT) (No. 2018R1A2B6007403). This work was supported by the National Research Foundation of Korea (NRF) grant funded by the Korean government (MSIT) through GCRC-SOP (No. 2011-0030013).

Conflicts of Interest: The authors declare no conflict of interest.

\section{References}

1. Choi, J.K.; Lee, S.G.; Park, Y.H.; Han, I.W.; Morris, J.W., Jr. High manganese austenitic steel for cryogenic applications. In Proceedings of the 22nd International Ocean and Polar Engineering Conference, Rhodes, Greece, 17-22 June 2012; International Society of Offshore and Polar Engineers: Mountain View, CA, USA, 2012.

2. Yu, J.W.; Yun, S.T.; Yoo, S.J.; Kim, K.H.; Seo, D.W.; Lee, S.G.; Han, I.W.; Jang, W.K.; Shin, G. Experimental study on the cryogenic tank made of high manganese steel. In Proceedings of the 25th International Ocean and Polar Engineering Conference, Kona, HI, USA, 21-26 June 2015; International Society of Offshore and Polar Engineers: Mountain View, CA, USA, 2015.

3. Gludovatz, B.; Hohenwarter, A.; Catoor, D.; Chang, E.H.; George, E.P.; Ritchie, R.O. A fracture-resistant high-entropy alloy for cryogenic applications. Science 2014, 345, 1153-1158. [CrossRef] [PubMed]

4. Yang, P.; Xie, Q.; Meng, L.; Ding, H.; Tang, Z. Dependence of deformation twinning on grain orientation in a high manganese steel. Scr. Mater. 2006, 55, 629-631. [CrossRef]

5. Grässel, O.; Krüger, L.; Frommeyer, G. High strength Fe-Mn-(Al, Si) TRIP/TWIP steels developmentProperties-Application. Int. J. Plast. 2000, 16, 1391-1409. [CrossRef]

6. Ueji, R.; Tsuchida, N.; Terada, D.; Tsuji, N.; Tanaka, Y.; Takemura, A.; Kunishige, K. Tensile properties and twinning behavior of high manganese austenitic steel with fine-grained structure. Scr. Mater. 2008, 59, 963-966. [CrossRef] 
7. Haase, C.; Bültmann, J.; Hof, J.; Ziegler, S.; Bremen, S.; Hinke, C.; Schwedt, A.; Prahl, U.; Bleck, W. Exploiting process-related advantages of selective laser melting for the production of high-manganese steel. Materials 2017, 10, 56. [CrossRef] [PubMed]

8. Pramanik, S.; Saleh, A.A.; Pereloma, E.V.; Gazder, A.A. Effect of isochronal annealing on the microstructure, texture and mechanical properties of a cold-rolled high manganese steel. Mater. Charact. 2018, 144, 66-76. [CrossRef]

9. Wang, H.; Sun, X.; Yang, P.; Mao, W.; Meng, L. Analysis of the transformation-induced plasticity effect during the dynamic deformation of high-manganese steel. J. Mater. Sci. Technol. 2015, 31, 191-198. [CrossRef]

10. Meng, L.; Yang, P.; Xie, Q.; Ding, H.; Tang, Z. Dependence of deformation twinning on grain orientation in compressed high manganese steels. Scr. Mater. 2007, 56, 931-934. [CrossRef]

11. Bayraktar, E.; Khalid, F.A.; Levaillant, C. Deformation and fracture behaviour of high manganese austenitic steel. J. Mater. Process. Technol. 2004, 147, 145-154. [CrossRef]

12. Dastur, Y.N.; Leslie, W.C. Mechanism of work hardening in Hadfield manganese steel. Metall. Mater. Trans. A Phys. Metall. Mater. Sci. 1981, 12, 749-759. [CrossRef]

13. Dobrzański, L.A.; Borek, W. Thermo-mechanical treatment of Fe-Mn-(Al, Si) TRIP/TWIP steels. Arch. Civ. Mech. Eng. 2012, 12, 299-304. [CrossRef]

14. Frommeyer, G.; Brüx, U. Microstructures and mechanical properties of high-strength Fe-Mn-Al-C light-weight TRIPLEX steels. Steel Res. Int. 2006, 77, 627-633. [CrossRef]

15. Curtze, S.; Kuokkala, V.T. Dependence of tensile deformation behavior of TWIP steels on stacking fault energy, temperature and strain rate. Acta Mater. 2010, 58, 5129-5141. [CrossRef]

16. Miura, R.; Nakajima, H.; Takahashi, Y.; Yoshida, K. 32Mn-7Cr Austenitic steel for cryogenic applications. In Advances in Cryogenic Engineering; Clark, A.F., Reed, R.P., Eds.; Springer: Boston, MA, USA, 1984; Volume 30, pp. 245-252.

17. Niendorf, T.; Lotze, C.; Canadinc, D.; Frehn, A.; Maier, H.J. The role of monotonic pre-deformation on the fatigue performance of a high-manganese austenitic TWIP steel. Mater. Sci. Eng. A Struct. 2009, 499, 518-524. [CrossRef]

18. Chin, K.G.; Kang, C.Y.; Shin, S.Y.; Hong, S.M.; Lee, S.H.; Kim, H.S.; Kim, K.H.; Kim, N.J. Effects of Al addition on deformation and fracture mechanisms in two high manganese TWIP steels. Mater. Sci. Eng. A Struct. 2011, 528, 2922-2928. [CrossRef]

19. Kikuchi, N.; Nabeshima, S.; Kishimoto, Y.; Matsushita, T.; Sridhar, S. Effect of Ti de-oxidation on solidification and post-solidification microstructure in low carbon high manganese steel. ISIJ Int. 2007, 47, 1255-1264. [CrossRef]

20. Niendorf, T.; Rubitschek, F.; Maier, H.J.; Niendorf, J.; Richard, H.A.; Frehn, A. Fatigue crack growth-Microstructure relationships in a high-manganese austenitic TWIP steel. Mater. Sci. Eng. A Struct. 2010, 527, 2412-2417. [CrossRef]

21. Srivastava, A.K.; Das, K. Microstructure and abrasive wear study of (Ti, W) C-reinforced high-manganese austenitic steel matrix composite. Mater. Lett. 2008, 62, 3947-3950. [CrossRef]

22. Frommeyer, G.; Brüx, U.; Neumann, P. Supra-ductile and high-strength manganese-TRIP/TWIP steels for high energy absorption purposes. ISIJ Int. 2003, 43, 438-446. [CrossRef]

23. Bouaziz, O.; Zurob, H.; Huang, M. Driving force and logic of development of advanced high strength steels for automotive applications. Steel Res. Int. 2013, 84, 937-947. [CrossRef]

24. Grajcar, A.; Kozłowska, A.; Grzegorczyk, B. Strain hardening behavior and microstructure evolution of high-manganese steel subjected to interrupted tensile tests. Metals 2018, 8, 122. [CrossRef]

25. Steineder, K.; Schneider, R.; Krizan, D.; Beal, C.; Sommitsch, C. Investigation on the microstructural evolution in a medium-Mn steel (X10Mn5) after intercritical annealing. HTM J. Heat Treat. Mater. 2015, 70, 19-25. [CrossRef]

26. Kowalska, J.; Ratuszek, W.; Witkowska, M.; Zielińska-Lipiec, A.; Kowalski, M. Microstructure and texture evolution during cold-rolling in the Fe-23Mn-3Si-3Al alloy. Arch. Metall. Mater. 2015, 60, 1789-1794. [CrossRef]

27. Grajcar, A.; Kciuk, M.; Topolska, S.; Plachcinska, A. Microstructure and corrosion behavior of hot-deformed and cold-strained high-Mn steels. J. Mater. Eng. Perform. 2016, 25, 2245-2254. [CrossRef]

28. Kucerova, L.; Opatova, K.; Kana, J.; Jirkova, H. High versatility of niobium and alloyed AHSS. Arch. Metall. Mater. 2017, 62, 1485-1491. [CrossRef] 
29. Radwanski, K. Application of FEG-SEM and EBSD methods for the analysis of the restoration processes occurring during continuous annealing of Dual-Phase steel strips. Steel Res. Int. 2015, 86, 1379-1390. [CrossRef]

30. Chaboche, J.L. Continuum damage mechanics: Part II-Damage growth, crack initiation, and crack growth J. Appl. Mech. 1988, 55, 65-72. [CrossRef]

31. Lemaitre, J. A continuous damage mechanics model for ductile fracture. J. Eng. Mater. Technol. Trans. ASME 1985, 107, 83-89. [CrossRef]

32. Lemaitre, J. Micro-mechanics of crack initiation. Int. J. Fract. 1990, 42, 87-99. [CrossRef]

33. De Souza Neto, E.A. A fast, one-equation integration algorithm for the Lemaitre ductile damage model. Commun. Numer. Methods Eng. 2002, 18, 541-554. [CrossRef]

34. Lee, C.S.; Yoo, B.M.; Kim, M.H.; Lee, J.M. Viscoplastic damage model for austenitic stainless steel and its application to the crack propagation problem at cryogenic temperatures. Int. J. Damage Mech. 2013, 22, 95-115. [CrossRef]

35. Chalal, H.; Abed-Meraim, F. Numerical predictions of the occurrence of necking in deep drawing processes. Metals 2017, 7, 455. [CrossRef]

36. Kim, S.K.; Lee, C.S.; Kim, J.H.; Kim, M.H.; Lee, J.M. Computational evaluation of resistance of fracture capacity for SUS304L of liquefied natural gas insulation system under cryogenic temperatures using ABAQUS user-defined material subroutine. Mater. Des. 2013, 50, 522-532. [CrossRef]

37. Kim, J.H.; Kim, S.K.; Kim, M.H.; Lee, J.M. Numerical model to predict deformation of corrugated austenitic stainless steel sheet under cryogenic temperatures for design of liquefied natural gas insulation system. Mater. Des. 2014, 57, 26-39. [CrossRef]

38. Sohn, S.S.; Hong, S.M.; Lee, J.H.; Suh, B.C.; Kim, S.K.; Lee, B.J.; Kim, N.J.; Lee, S.H. Effects of Mn and Al contents on cryogenic-temperature tensile and Charpy impact properties in four austenitic high-Mn steels. Acta Mater. 2015, 100, 39-52. [CrossRef]

39. Park, D.H.; Choi, S.W.; Kim, J.H.; Lee, J.M. Cryogenic mechanical behavior of 5000- and 6000-series aluminum alloys: Issues on application to offshore plans. Cryogenics 2015, 68, 44-58. [CrossRef]

40. Kim, S.K.; Lee, C.S.; Kim, J.H.; Kim, M.H.; Noh, B.J.; Matsumoto, T.; Lee, J.M. Estimation of fatigue crack growth rate for $7 \%$ nickel steel under room and cryogenic temperatures using damage-coupled finite element analysis. Metals 2015, 5, 603-627. [CrossRef]

41. Aravas, N. On the numerical integration of a class of pressure-dependent plasticity. Int. J. Numer. Methods Eng. 1987, 24, 1395-1416. [CrossRef]

42. Jin, K.; Guo, X.; Tao, J.; Wang, H.; Kim, N.S.; Gu, Y. A model of one-surface cyclic plasticity with Lemaitre damage criterion for plastic instability prediction in the incremental forming process. Int. J. Mech. Sci. 2016, 114, 88-97. [CrossRef]

43. Hu, P.; Shi, D.; Ying, L.; Shen, G.; Liu, W. The finite element analysis of ductile damage during hot stamping of 22MnB5 steel. Mater. Des. 2015, 69, 141-152. [CrossRef]

44. Anderson, D.; Winkler, S.; Bardelcik, A.; Worswick, M.J. Influence of stress triaxiality and strain rate on the failure behavior of a dual-phase DP780 steel. Mater. Des. 2014, 60, 198-207. [CrossRef]

(C) 2018 by the authors. Licensee MDPI, Basel, Switzerland. This article is an open access article distributed under the terms and conditions of the Creative Commons Attribution (CC BY) license (http://creativecommons.org/licenses/by/4.0/). 